Total invtravenous anesthesia with midazolam, ketamine, and xylazine or detomidine following induction with tiletamine, zolazepam, and xylazine in red deer (Cervus elaphus hippelaphus) undergoing surgery

Auer, Ulrike ; Wenger, Sandra ; Beigelböck, Christoph ; Zenker, Wolfgang ; Mosing, Martina

\begin{abstract}
Sixteen captive female red deer were successfully anesthetized to surgically implant a telemetry system. The deer were immobilized with (mean \pm SD) $1.79 \pm 0.29 \mathrm{mg} / \mathrm{kg}$ xylazine and $1.79 \pm 0.29 \mathrm{mg} / \mathrm{kg}$ tiletamine $/$ zolazepam given intramuscularly with a dart gun. Anesthesia was maintained for $69 \pm 2 \mathrm{~min}$ using a total intravenous protocol with a catheter placed in the jugular vein. Group X received xylazine $(0.5 \pm 0.055 \mathrm{mg} / \mathrm{kg} / \mathrm{hr})$ and group D, detomidine $(2 \pm 0.22 \mu \mathrm{g} / \mathrm{kg} / \mathrm{hr})$, both in combination with ketamine $(2 \pm 0.02 \mathrm{mg} / \mathrm{kg} / \mathrm{hr})$ and midazolam $(0.03 \pm 0.0033$ $\mathrm{mg} / \mathrm{kg} / \mathrm{hr}$ ), as a constant rate infusion. Anesthesia was reversed with $0.09 \pm 0.01 \mathrm{mg} / \mathrm{kg}$ atipamezole and $8.7 \pm 1.21$ $\mu \mathrm{g} / \mathrm{kg}$ sarmazenil given intravenously in both groups. These drug combinations provided smooth induction, stable anesthesia for surgery, and rapid recovery. Respiratory depression and mild hypoxemia were seen, and we, therefore, recommend using supplemental intranasal oxygen.
\end{abstract}

DOI: https://doi.org/10.7589/0090-3558-46.4.1196

Posted at the Zurich Open Repository and Archive, University of Zurich

ZORA URL: https://doi.org/10.5167/uzh-36361

Journal Article

Originally published at:

Auer, Ulrike; Wenger, Sandra; Beigelböck, Christoph; Zenker, Wolfgang; Mosing, Martina (2010). Total invtravenous anesthesia with midazolam, ketamine, and xylazine or detomidine following induction with tiletamine, zolazepam, and xylazine in red deer (Cervus elaphus hippelaphus) undergoing surgery. Journal of Wildlife Diseases, 46(4):1196-1203.

DOI: https://doi.org/10.7589/0090-3558-46.4.1196 


\title{
TOTAL INTRAVENOUS ANESTHESIA WITH MIDAZOLAM, KETAMINE, AND XYLAZINE OR DETOMIDINE FOLLOWING INDUCTION WITH TILETAMINE, ZOLAZEPAM, AND XYLAZINE IN RED DEER (CERVUS ELAPHUS HIPPELAPHUS) UNDERGOING SURGERY
}

\author{
Ulrike Auer, ${ }^{1,6}$ Sandra Wenger, ${ }^{2}$ Christoph Beigelböck, ${ }^{3}$ Wolfgang Zenker, ${ }^{4}$ and \\ Martina Mosing ${ }^{5}$ \\ ${ }^{1}$ Division of Anaesthesiology and Perioperative Intensive Care, University of Veterinary Medicine, Veterinärplatz 1, \\ 1210 Vienna, Austria \\ ${ }^{2}$ Clinic for Zoo Animals, Exotic Pets and Wildlife, Vetsuisse Faculty, University of Zurich, Winterthurerstrasse 260, 8057 \\ Zürich, Switzerland \\ ${ }^{3}$ Research Institute of Wildlife Ecology, University of Veterinary Medicine, Savoyenstrasse 1, 1160 Vienna, Austria \\ ${ }^{4}$ Praxis für Zootiere und Exoten, Kleintierpraxis, Neuwiesenstr. 6, 8610 Uster, Switzerland \\ ${ }^{5}$ Equine Hospital, The University of Liverpool, Leahurst, Chester High Road, Neston, South Wirral CH64 7TE, UK \\ ${ }^{6}$ Corresponding author (email: Ulrike.Auer@vetmeduni.ac.at)
}

ABSTRACT: Sixteen captive female red deer were successfully anesthetized to surgically implant a telemetry system. The deer were immobilized with (mean \pm SD) $1.79 \pm 0.29 \mathrm{mg} / \mathrm{kg}$ xylazine and $1.79 \pm 0.29 \mathrm{mg} / \mathrm{kg}$ tiletamine/zolazepam given intramuscularly with a dart gun. Anesthesia was maintained for $69 \pm 2$ min using a total intravenous protocol with a catheter placed in the jugular vein. Group X received xylazine $(0.5 \pm 0.055 \mathrm{mg} / \mathrm{kg} / \mathrm{hr})$ and group D, detomidine $(2 \pm 0.22 \mu \mathrm{gg} / \mathrm{kg} /$ $\mathrm{hr})$, both in combination with ketamine $(2 \pm 0.02 \mathrm{mg} / \mathrm{kg} / \mathrm{hr})$ and midazolam $(0.03 \pm 0.0033 \mathrm{mg} / \mathrm{kg} /$ $\mathrm{hr})$, as a constant rate infusion. Anesthesia was reversed with $0.09 \pm 0.01 \mathrm{mg} / \mathrm{kg}$ atipamezole and $8.7 \pm 1.21 \mu \mathrm{g} / \mathrm{kg}$ sarmazenil given intravenously in both groups. These drug combinations provided smooth induction, stable anesthesia for surgery, and rapid recovery. Respiratory depression and mild hypoxemia were seen, and we, therefore, recommend using supplemental intranasal oxygen.

Key words: Detomidine, ketamine, midazolam, red deer, total intravenous anesthesia, xylazine.

\section{INTRODUCTION}

Approximately five million deer live in captivity worldwide and interest in farmed deer is growing exponentially (Hudson, 2001). Procedures such as hoof care, treatment of dystocia or amputation of antlers are commonly performed in deer, and an in-depth knowledge about immobilization and anesthesia is necessary. Many sedative and anesthetic protocols have been evaluated in various deer species during the past two decades. Numerous reports describe the use of injectable anesthetics alone or in combination with local anesthesia for short surgical procedures. Potent opioids or cyclohexamines (tiletamine, ketamine) in combination with benzodiazepines or alpha-2 adrenoceptor agonists are commonly used for immobilization and short-term anesthesia in red deer (McKelvey and Simpson, 1985; Caulkett, 1997; Janovsky et al., 2000). For prolonged or invasive procedures, inhalation anesthesia is recommended (Caulkett, 1997). As inhalation anesthesia can be difficult to perform under field conditions, a safe protocol using total intravenous anesthesia (TIVA) would be valuable.

The aims of this study were to evaluate a TIVA protocol using a combination of midazolam, ketamine, and xylazine or detomidine to maintain anesthesia in red deer and to investigate the effects of partial antagonization of this combination with atipamezole and sarmazenil.

\section{MATERIALS AND METHODS}

\section{Animals}

Sixteen female free-ranging red deer (Cervus elaphus hippelaphus), living in a 45-ha, forested portion of the Research Institute of Wildlife Ecology in Vienna, Austria $\left(48^{\circ} 12^{\prime} 0^{\prime \prime} \mathrm{N}, 16^{\circ} 22^{\prime} 0^{\prime \prime} \mathrm{E}\right)$, were immobilized. Animals had a mean \pm SD age of $4.1 \pm 1.3 \mathrm{yr}$ 
(range, 1.5-6 yr) and a body weight of $120 \pm 15 \mathrm{~kg}$ (range, 90-135 kg). Body weight was estimated by one person before darting; after induction, the exact weight was determined by weighing with an electronic balance. Surgery was performed to implant a selfconstructed telemetry system as part of an etho-ecologic project. A ventral midline neck incision was made through the skin, and the subcutaneous tissue was separated by blunt dissection to form a pouch on the left ventrolateral aspect of the neck. Two incisions were made along the caudal ventral midline of the pouch for placement of the electrocardiogram (ECG) electrodes. Electrodes were pulled from the transmitter pouch through a subcutaneous tunnel prepared with a sterile catheter. The transmitter and electrodes were fixed to the subcutis, and the skin incisions were closed with absorbable suture material (Giacometti et al., 2001). This study was approved by the Institutional Ethics Committee of the Veterinary University of Vienna and had governmental approval (reference, GZ 68.205/88-BvGt/2002).

\section{Study design}

A parallel study design was used, and animals were randomly divided into two groups. Group X received a TIVA protocol using midazolam, ketamine, and xylazine given as a continuous rate infusion (CRI) after initial immobilization with tiletamine, zolazepam, and xylazine. In group D, anesthesia was maintained using a CRI with midazolam, ketamine, and detomidine.

\section{Anesthesia}

Two days before surgery the deer were brought into a 1-ha, restricted area. Food, but not water, was withheld for $24 \mathrm{hr}$. Lyophilized powder of $500 \mathrm{mg}$ tiletamine-zolazepam (Zoletil, Virbac, Carros, France) and $500 \mathrm{mg}$ of lyophilized xylazine powder (Rompun TS, Bayer, Leverkusen, Germany) were dissolved in $5 \mathrm{ml}$ water for injection. This resulted in a concentration of $50 \mathrm{mg}$ tiletamine, $50 \mathrm{mg}$ zolazepam, and $100 \mathrm{mg}$ xylazine per milliliter of solution. The body weight of the animal was estimated, and a 3-ml, plastic dart (Telinject G.U.T., Roemerberg, Germany) was prepared. The animal was darted with 2 to $2.5 \mathrm{ml}$ of the solution intramuscularly in the upper hind leg or shoulder area using a $\mathrm{CO}_{2}$-pressurized dart gun (Daninject, Selerup, Denmark). Time (in minutes) from darting to initial effect with head on the ground (onset time) was recorded. Thereafter, the animals were transported from the enclosure to the operating theater (dis- tance, approximately $600 \mathrm{~m}$ ), where endotracheal intubation was performed. Time from darting to intubation (intubation time) was recorded.

A catheter (Intraflon2, $12 \mathrm{G}$, Vycon, Ecoune, France) was placed in the left jugular vein for intravenous (IV) administration of $10 \mathrm{ml} / \mathrm{kg} / \mathrm{hr}$ lactated Ringer's solution (Ringer Lactat "Fresenius," Fresenius Kabi Austria $\mathrm{GmbH}$, Graz, Austria) and anesthesia maintenance using CRI. After endotracheal intubation, the tube was connected to a circle system delivering an oxygen/air mixture with an inspiratory oxygen concentration $\left(\mathrm{FIO}_{2}\right)$ of 30-50\%. Animals breathed spontaneously. The animals were positioned in right lateral recumbency with the left foreleg pulled forward.

To prepare the CRI solution, $250 \mathrm{mg}$ xylazine (Xylasol, Dr. E. Gräub AG, Berne, Switzerland) for group $\mathrm{X}$, or $1.4 \mathrm{mg}$ detomidine (Domosedan, Pfizer, Vienna, Austria) for group D, plus the 1,000 mg ketamine $(10 \%$ Narketan, Vetoquinol Austria GmbH, Vienna, Austria) and $15 \mathrm{mg}$ midazolam (Midazolam Mayrhofer Pharmazeutika, Vienna, Austria) were mixed in $500 \mathrm{ml}$ saline $(0.9 \% \mathrm{NaCl}$ "Fresenius," Fresenius Kabi). This resulted in a concentration of $0.5 \mathrm{mg} / \mathrm{ml}$ xylazine or $2.0 \mu \mathrm{g} /$ $\mathrm{ml}$ detomidine, $2 \mathrm{mg} / \mathrm{ml}$ ketamine, and $0.03 \mathrm{mg} / \mathrm{ml} \mathrm{midazolam}$. For the first $20 \mathrm{~min}$, an infusion rate of $1.2 \mathrm{ml} / \mathrm{kg} / \mathrm{hr}$ was administered via an infusion pump (Asena ${ }^{\mathrm{TM}}$, Alaris Medical UK Ltd, Basingstoke, Hampshire, UK). Thereafter, CRI rate was reduced stepwise in $10 \%$ increments every $10 \mathrm{~min}$. The duration of CRI administration and the total volume given were noted.

After surgery, the animals were brought back to the restricted area. Twenty minutes after the end of anesthesia, a combination of $10 \mathrm{mg}$ atipamezole (Antisedan, Pfizer) and $1 \mathrm{mg}$ sarmazenil (Sarmasol, Dr. E. Gräub AG, Bern, Switzerland) was administered by IV. The catheter and endotracheal tube were removed. Time from administration of the antagonists to sternal recumbency (sternal time) and standing (up time) were recorded. Quality of recovery was evaluated as excellent (standing on first attempt, normal gait without ataxia), good (standing on first attempt with minimal ataxia, moving with unsteady gait) or poor (requiring more than one attempt to standing, moderate to severe ataxia, and falling over). Animals were observed for $4 \mathrm{hr}$ after surgery.

\section{Monitoring}

A catheter (Vasocan Braunüle, $0.9 \times 25 \mathrm{~mm}$, B. Braun, Melsungen, Germany) was placed in 
the auricular artery for invasive measurement of arterial blood pressure (Combitrans Monitoring-Set Arteriell, Fa., Braun). The blood pressure transducer was positioned and calibrated to atmospheric pressure at the level of the sternum. An arterial blood sample for blood gas analysis was taken in four deer in each group before the endotracheal tube was connected to the circle system and 20 and 40 min after connection to the circle system. The blood samples were analyzed immediately after sampling using a portable blood gas analyzer (I-STAT Portable Clinical Analyzer; I-STAT Corporation, East Windsor, New Jersey, USA). An oxygen partial pressure $\left(\mathrm{PaO}_{2}\right)$ of lower than $60 \mathrm{mmHg}(8 \mathrm{kPa})$ at the second blood gas analysis was seen as the cutoff point to increase $\mathrm{FIO}_{2}$ from $30 \%$ to $50 \%$ to $100 \%$. Heart rate (HR) was determined from the ECG in a base-apex lead (HP CMS Monitor M1001A, Hewlett Packard, Boeblingen, Germany). Respiratory rate ( $R R$ ) and end-tidal carbon dioxide tension $\left(\mathrm{PECO}_{2}\right)$ were evaluated using a side stream capnograph (Nellcor, Hayward, California, USA). The same device was used to evaluate hemoglobin oxygen saturation $\left(\mathrm{SpO}_{2}\right)$ by placing the probe of the pulse oximeter on the tongue. Tidal volume (VT) was measured using a Wright spirometer (Dräger, Lübeck, Germany), positioned in the expiratory limb of the circle system. For measuring core body temperature (T), an esophageal temperature probe was used (HPM1008P, HP CMS Monitor, Hewlett Packard). All parameters were manually recorded at 10-min intervals. Any side effects throughout the time under anesthesia were recorded.

\section{Statistical analyses}

Results are expressed as mean \pm SD. Differences in $\mathrm{HR}, \mathrm{RR}, \mathrm{PECO}_{2}$, and $\mathrm{T}$ between the two groups were analyzed using an unpaired Student's $t$-test for normally distributed data and the Wilcoxon rank-sum test for nonparametric data. One-way analysis of variance (ANOVA) was used to compare repeatedly measured parameters within a group. Statistical significance was determined at $P<0.05$.

\section{RESULTS}

The mean dose for initial immobilization with xylazine and tiletamine/zolazepam was $1.79 \pm 0.29 \mathrm{mg} / \mathrm{kg}$ and $1.79 \pm 0.29 \mathrm{mg} / \mathrm{kg}$, respectively. Onset time, intubation time, and duration of CRI were $8.2 \pm 3.6 \mathrm{~min}, 30 \pm 19 \mathrm{~min}$, and
$69 \pm 2$ min, respectively. Mean infusion rate was $1 \pm 0.1 \mathrm{ml} / \mathrm{kg} / \mathrm{hr}$ with a total volume of $138 \pm 18.9 \mathrm{ml}$. Mean dose of xylazine and detomidine was $0.54 \pm$ $0.03 \mathrm{mg} / \mathrm{kg} / \mathrm{hr}$ and $1.55 \pm 0.6 \mathrm{mcg} / \mathrm{kg} / \mathrm{hr}$, respectively, and was $2.1 \pm 0.2 \mathrm{mg} / \mathrm{kg} / \mathrm{hr}$ for ketamine and $3.2 \pm 0.4 \mathrm{mg} / \mathrm{kg} / \mathrm{hr}$ for midazolam. There were no significant differences between groups. Total time of anesthesia from darting to end of recovery period was $116 \pm 15 \mathrm{~min}$.

Heart rate, mean blood pressure, $\mathrm{RR}$, and $\mathrm{PECO}_{2}$ were higher in group $\mathrm{X}$ than group D, but this was not statistically significant. Tidal volume was significantly lower in group $\mathrm{X}$ at time points 25, 35, 45, 55 , and 65 min (Table 1). Depth of anesthesia was easy to adapt in both groups

Results of blood gas analyses are summarized in Table 2. Both groups showed hypercapnia, respiratory acidosis, and decreased $\mathrm{PaO}_{2}$. No significant differences were seen for $\mathrm{PaO}_{2}$ between groups. Mean $\mathrm{PaO}_{2}$ before oxygen supplementation was $82 \pm 19.7 \mathrm{mmHg}(10.8 \pm 2.6 \mathrm{kPa})$ and, after connection to the anesthetic circle system, was $105 \pm 18.5 \mathrm{mmHg}$ $(14 \pm 2.4 \mathrm{kPa})$. In both groups, $\mathrm{PaO}_{2}$ increased significantly over time. The partial pressure of carbon dioxide $\left(\mathrm{PaCO}_{2}\right)$ was significantly higher at all time points in group $\mathrm{X}(P<0.001)$ than in group $\mathrm{D}$.

The mean doses of sarmazenil and atipamezole were $8.7 \pm 1.2 \mathrm{mg} / \mathrm{kg}$ and $0.09 \pm 0.01 \mathrm{mg} / \mathrm{kg}$, respectively. Times to reach sternal recumbency and to standing after antagonization were $0.9 \pm 0.6 \mathrm{~min}$ and 1.9 $\pm 1.6 \mathrm{~min}$, respectively. Mean duration of recovery was $21.7 \pm 2.6 \mathrm{~min}$. No differences were seen between groups. Quality of recovery was excellent in 15 deer. One deer in group $X$ received no reversal because it recovered spontaneously 14 min after the end of anesthesia. Another deer in group $\mathrm{X}$ became recumbent again $20 \mathrm{~min}$ after reversal and, therefore, received an additional bolus of $10 \mathrm{mg}$ atipamezole and $1 \mathrm{mg}$ sarmazenil IV. Heart rates recorded from the telem- 
TABLE 1. Physiologic variables of red deer maintained anesthetized with a continuous rate infusion of midazolam, ketamine and xylazine or detomidine. Numbers are mean \pm SD.

\begin{tabular}{|c|c|c|c|c|c|c|c|}
\hline \multirow[b]{2}{*}{ Variable $^{\mathrm{a}}$} & \multicolumn{7}{|c|}{ Time $(\min )$} \\
\hline & 5 & 15 & 25 & 35 & 45 & 55 & 65 \\
\hline HR X (beats/min) & $50 \pm 15$ & $44 \pm 5.5$ & $46 \pm 5.9$ & $48 \pm 6.8$ & $50 \pm 8.2$ & $47 \pm 3.9$ & $45 \pm 6.7$ \\
\hline HR D (Beats/min) & $43 \pm 5.2$ & $42 \pm 3.9$ & $44 \pm 6.1$ & $44 \pm 8.3$ & $46 \pm 11$ & $45 \pm 12$ & $47 \pm 15$ \\
\hline SAP X (mmHg) & $104 \pm 13.8$ & $109 \pm 15.8$ & $107 \pm 14.9$ & 10612.8 & $104 \pm 13.5$ & $101 \pm 14.1$ & $97 \pm 15.5$ \\
\hline SAP D (mmHg) & $117 \pm 12.8$ & $115 \pm 15.6$ & $113 \pm 17.1$ & $108 \pm 21.1$ & $113 \pm 18.6$ & $113 \pm 19.5$ & $111 \pm 19.6$ \\
\hline RR X (breaths/min) & $23 \pm 13.4$ & $28 \pm 11.9$ & $32 \pm 10.8$ & $31 \pm 9.8$ & $28 \pm 10.9$ & $26 \pm 11.5$ & $22 \pm 10.9$ \\
\hline RR D (breaths/min) & $18 \pm 15.6$ & $17 \pm 12.6$ & $19 \pm 14.9$ & $19 \pm 12.1$ & $22 \pm 13.4$ & $21 \pm 10.7$ & $18 \pm 8.7$ \\
\hline \multicolumn{8}{|l|}{$\mathrm{PECO}_{2} \mathrm{X}$} \\
\hline $\mathrm{mmHg}$ & $63 \pm 14.6$ & $63 \pm 8.7$ & $65 \pm 13.1$ & $65 \pm 9.4$ & $70 \pm 10.5$ & $72 \pm 9.6$ & $80 \pm 15.9$ \\
\hline $\mathrm{kPa}$ & $8.4 \pm 1.9$ & $8.4 \pm 1.2$ & $8.6 \pm 1.7$ & $8.6 \pm 1.3$ & $9.3 \pm 1.4$ & $9.6 \pm 1.3$ & $10.6 \pm 2.1$ \\
\hline \multicolumn{8}{|l|}{$\mathrm{PECO}_{2} \mathrm{D}$} \\
\hline $\mathrm{mmHg}$ & $55 \pm 15.4$ & $59 \pm 14.3$ & $63 \pm 8.7$ & $63 \pm 9.9$ & $61 \pm 15.5$ & $66 \pm 9.1$ & $65 \pm 9.3$ \\
\hline $\mathrm{kPa}$ & $7.3 \pm 2.1$ & $7.8 \pm 1.9$ & $8.4 \pm 1.2$ & $8.4 \pm 1.3$ & $8.1 \pm 2.1$ & $8.8 \pm 1.2$ & $8.6 \pm 1.2$ \\
\hline VT X (ml/breath) & $450 \pm 94$ & $513 \pm 155$ & $469 \pm 65^{*}$ & $506 \pm 90 *$ & $494 \pm 77^{*}$ & $457 \pm 109 *$ & $383 \pm 76^{*}$ \\
\hline $\mathrm{V}_{\mathrm{T}} \mathrm{D}(\mathrm{ml} /$ breath $)$ & $586 \pm 237$ & $669 \pm 188$ & $681 \pm 171$ & $731 \pm 148$ & $688 \pm 168$ & $695 \pm 130$ & $728 \pm 86$ \\
\hline $\mathrm{T} X(\mathrm{C})$ & $38 \pm 0.6$ & $38 \pm 0.5$ & $39 \pm 0.5$ & $39 \pm 0.5$ & $38 \pm 0.5$ & $39 \pm 0.4$ & $39 \pm 0.5$ \\
\hline $\mathrm{T} \mathrm{D}(\mathrm{C})$ & $38 \pm 1.1$ & $39 \pm 0.9$ & $39 \pm 0.7$ & $39 \pm 0.7$ & $39 \pm 0.7$ & $39 \pm 0.7$ & $39 \pm 0.5$ \\
\hline
\end{tabular}

* Significant difference $(P<0.001)$ between xylazine and detomidine.

${ }^{\text {a }} \mathrm{X}=$ xylazine; $\mathrm{D}=$ detomidine; $\mathrm{HR}=$ heart rate; $\mathrm{SAP}=$ systolic arterial blood pressure; $\mathrm{RR}=$ respiratory rate $; \mathrm{PECO}_{2}=$ end expiratory carbon dioxide; $\mathrm{V}_{\mathrm{T}}=$ tidal volume; $\mathrm{T}=$ temperature.

etry systems varied from $44 \pm 20$ to $77 \pm 23$ thesia for a surgical procedure lasting in the first $24 \mathrm{hr}$ after end of anesthesia, longer than $1 \mathrm{hr}$ and can easily be applied and no significant differences were seen under field conditions. The major side between the two groups.

\section{DISCUSSION}

Inhalation anesthesia is recommended for prolonged or invasive procedures in cervids (Caulkett, 1997). Expensive and bulky equipment is necessary to maintain inhalation anesthesia under field conditions. The TIVA protocol used in our deer provided a good level of aneseffect seen in this study was respiratory depression causing hypercapnia and mild hypoxemia. Therefore, oxygen supplementation is highly recommended. Nasal insufflation of oxygen at $10 \mathrm{l} / \mathrm{min}$ has been proven to reduce hypoxemia under field conditions (Read et al., 2001, Mich et al., 2008).

Blood gas analyses revealed hypercapnia, respiratory acidosis, and decreased $\mathrm{PaO}_{2}$ in both groups. However, higher

TABLE 2. Blood gas values of four red deer in group xylazine and four in group detomidine that were maintained anesthetized with a continuous rate infusion of midazolam, ketamine, and xylazine or detomidine. ${ }^{\text {a }}$

\begin{tabular}{cccccccc}
\hline Group & Sampling interval & $\mathrm{PaO}_{2}(\mathrm{mmHg})$ & $\mathrm{PaCO}_{2}(\mathrm{mmHg})$ & Base excess & $\mathrm{HCO}_{3}$ & $\mathrm{pH}$ & Lactate \\
\hline Xylazine & 1 & $82.7 \pm 19.7$ & $75.1 \pm 6.8^{*}$ & $4 \pm 3.4$ & $32 \pm 3.4$ & $7.2 \pm 0.1$ & $0.9 \pm 0.4$ \\
$(n=4)$ & 2 & $88.5 \pm 4.5$ & $79.1 \pm 11.2^{*}$ & $4.5 \pm 3$ & $32 \pm 3.5$ & $7.2 \pm 0.1$ & $1 \pm 0.6$ \\
& 3 & $105.5 \pm 18.2$ & $76.3 \pm 12.2^{*}$ & $3.8 \pm 1.3$ & $32 \pm 1.2$ & $7.2 \pm 0.1$ & $0.7 \pm 0.3$ \\
Detomidine & 1 & $58.2 \pm 11.8$ & $59.4 \pm 9.3$ & $3.1 \pm 3.2$ & $29.6 \pm 3.4$ & $7.3 \pm 0.1$ & $1.6 \pm 1.4$ \\
$(n=4)$ & 2 & $79.5 \pm 17.9$ & $67 \pm 9.6$ & $5.4 \pm 2.4$ & $31.5 \pm 3.3$ & $7.3 \pm 0.1$ & $1.3 \pm 0.9$ \\
& 3 & $107.7 \pm 67.6$ & $67.9 \pm 8.5$ & $6.1 \pm 2.7$ & $31.8 \pm 4$ & $7.3 \pm 0.1$ & $0.8 \pm 0.5$ \\
\hline
\end{tabular}

* Significant differences $(P<0.001)$ between xylazine and detomidine.

${ }^{\text {a }} \mathrm{PaO}_{2}=$ oxygen partial pressure; $\mathrm{PaCO}_{2}=$ partial pressure of carbon dioxide; $\mathrm{HCO}_{3}=$ bicarbonate. 
$\mathrm{PaCO}_{2}$ and $\mathrm{PECO}_{2}$ levels were seen in the xylazine group. This indicates that the combination that included xylazine caused more respiratory depression than the detomidine combination did. Along with the higher $\mathrm{CO}_{2}$ levels, higher $\mathrm{PaO}_{2}$ levels were seen in the xylazine group. Similar findings were reported with a xylazinetiletamine-zolazepam mixture in wapiti (Cervus canadensis; Read et al., 2001). The most likely explanation for this finding is a higher ventilation/perfusion mismatch and intrapulmonary shunt volume in group $\mathrm{D}$ leading to lower $\mathrm{PaO}_{2}$ values compared with those for group X. However, because $\mathrm{Pa} / \mathrm{PaO}_{2}$ differences were not evaluated because the inspiratory oxygen concentration was not measured, this remains an assumption. Ventilation/ perfusion mismatch and intrapulmonary shunt volume are not directly correlated to pulmonary ventilation, which was better maintained in group D, resulting in lower $\mathrm{PaCO}_{2}$ levels.

Combinations of tiletamine-zolazepam and xylazine and prolongation of anesthesia with ketamine are widely used for the immobilization of cervids (Caulkett, 1997; Galka et al., 1999; Fernandez-Moran et al., 2000; Janovsky et al., 2000; Read et al., 2001). These combinations can lead to prolonged recovery because of the accumulation of ketamine and norketamine, its first metabolite. An overhang with ketamine or norketamine can lead to increased muscle tone and increased oxygen consumption during recovery. Therefore, alternative protocols, combining ketamine with muscle relaxants and sedatives, could be useful because the ketamine dose can be reduced. A TIVA protocol, including guaifenesin, can be used in cattle and small ruminants, but cervids seem to be particularly sensitive to toxic side effects of guaifenesin, including extensor rigidity and opisthotonus (Lin et al., 1993; Riebold, 1996; Caulkett, 1997). The administration of the benzodiazepine midazolam for central muscle relaxation, instead of guaifenesin, is a relatively new technique.
Unlike diazepam, midazolam is water soluble and can, therefore, be mixed with other drugs in a CRI solution. The use of midazolam in combination with ketamine for induction in wild ruminants is limited to one case report in a buffalo (Syncerus caffer; Stegmann, 2004). Midazolam, ketamine, and three different alpha-2 adrenoceptor agonists (xylazine, detomidine, and medetomidine) in combination with a low dose of isoflurane was used for maintenance in horses (Equus caballus; Mosing et al., 2007). Xylazine and detomidine were preferred over medetomidine as the former two alpha-2 adrenoceptor agonists are licensed for ruminants in the European Union (European Commission, 2009). This is an important issue in the case of deer farmed for meat production within the European Union. Using medetomidine as part of the maintenance protocol, instead of xylazine or detomidine, for wildlife captures (in which case, the cascade must not be considered) might result in quicker onset times, less stressful responses, more cardiovascular stability, and quicker recovery when using atipamezole (Jalanka and Roeken, 1990; Caulkett et al., 2000; Fernández-Morán et al. 2000; Mich et al., 2008)

When continuous-rate infusions are used to provide long-term anesthesia, drugs with a short-elimination half-life are preferable to avoid accumulation. Midazolam has a relatively short elimination half-life, which makes it a valuable drug that can be given via CRI (Hall et al., 1988; Fragen, 1997). As already mentioned, the limitation of the benzodiazepine-ketamine CRI is the ketamine component. Pharmacokinetic studies done in horses revealed no cumulative effect after administration of ketamine CRI lasting 60 min. Norketamine, the active metabolite of ketamine was detected throughout the study period. Recovery was smooth in all animals (Nolan et al., 1996). In another study, two of six ponies showed some excitement and ataxia after $120 \mathrm{~min}$ of ketamine-climazolam CRI (Bettschart- 
Wolfensberger et al., 1996). The reason for these poor-quality recoveries is discussed as being an accumulation of norketamine. However, no ketamine-associated side effects were noted during recovery for our red deer. The antagonists were given only 20 min after termination of ketamine infusion in our red deer, and this might have reduced possible hallucinogenic side effects of ketamine.

Regurgitation and aspiration can occur when protective airway reflexes are abolished in ruminants. This is an important factor because cervids are difficult to intubate, compared with small animals and horses. Protective reflexes are mostly maintained with ketamine and are abolished under inhalation anesthesia. No regurgitation was observed in this study using midazolam, ketamine and xylazine, or detomidine anesthesia. We would still recommend intubating deer for prolonged procedures, even under field conditions, to maintain airway patency and avoid aspiration.

Side effects of xylazine described in cervids, besides respiratory and cardiovascular depression, include ruminal tympany, regurgitation, and decreased thermoregulation ability (Caulkett, 1997). In wapiti, dose recommendations for xylazine are $1 \mathrm{mg} / \mathrm{kg}$. For white-tailed deer (Odocoileus virginianus) and mule deer (Odocoileus hemionus) higher doses $(2 \mathrm{mg} / \mathrm{kg}$ ) are recommended (Caulkett, 1997). The xylazine dose used in our study falls within this range. No regurgitation or tympany was observed.

Prolonged recoveries might lead to decreased survival of deer in the wild. Free-ranging animals have to respond quickly to dangerous environmental situations. For this reason, reversible protocols are preferred for immobilization of wildlife. In this study, a mixture of atipamezole and sarmazenil IV was used for antagonization. Atipamezole is the most potent and selective alpha- 2 adrenoceptor antagonist, and is primarily used for the reversal of medetomidine. Its use, to antagonize detomidine after continuous rate infusion of up to $110 \mathrm{~min}$, has been evaluated in horses (van Dijk et al., 2003). After atipamezole, all horses could walk without ataxia, and no relapse into sedation occurred for $1 \mathrm{hr}$ after antagonization. Atipamezole is also recommended in deer after the use of detomidine (Hall et al., 2001). In our study, no deer in group D showed excitement or relapse into sedation during the observation period.

The effectiveness of atipamezole to antagonize xylazine has been shown in white-tailed deer, Arabian oryx (Oryx leucoryx), grey duikers (Sylvicapra grimmia), and axis deer (Axis axis; Arnemo et al., 1993; Ancrenaz, 1994; Nicholls et al., 1996; Miller et al., 2004). Reversal was not constant in all species, and some animals showed incomplete reversal or resedation after 2 to $5 \mathrm{hr}$ (Ancrenaz, 1994; Nicholls et al., 1996; Miller et al., 2004). On the other hand, one of eight axis deer sedated with xylazine alone showed signs of overalertness after reversal with atipamezole IV, and no cases of resedation were observed (Arnemo et al., 1993). One animal from group $\mathrm{X}$ showed resedation $20 \mathrm{~min}$ after reversal, and an additional bolus of atipamezole and sarmazenil had to be given by IV.

Sarmazenil is a partial inverse benzodiazepine receptor agonist and was used to antagonize the effects of midazolam. Benzodiazepines bind to a specific benzodiazepine receptor site on $\gamma$-aminobutyric acid $A$ receptors $\left(\mathrm{GABA}_{\mathrm{A}}\right)$ in the brain. Genuine antagonists, like flumazenil, bind to the same site as benzodiazepines, without affecting the GABA-binding. Therefore, the only pharmacological effect is that benzodiazepine agonists are displaced from the receptor site. Flumazenil has been used in many species in veterinary anesthesia. One report in whitetailed deer did not affect recovery time (Miller et al., 2004). Sarmazenil, on the other hand, interacts with the benzodiazepine binding site on the receptor and reduces GABA binding and GABA-in- 
duced chloride flux (Haefely, 1983). Sarmazenil is the specific antagonist of climazolam and is mainly used in horses (Bettschart-Wolfensberger et al., 1996). Both sarmazenil and flumazenil have stimulatory effects on locomotion and on exploratory behavior in mice (Mus musculus) and therefore might reverse the sedative effect of other drugs as well (Jackson and Nutt, 1992). In our study, sarmazenil, given together with atipamezole, provided rapid and complete reversal without causing excitation or obvious hypermotility.

In conclusion, we describe two feasible TIVA protocols for red deer to perform prolonged procedures under field conditions. No adverse effects like tympany or regurgitation were observed in any of the 16 deer. However, the supplementation of oxygen was crucial to avoid hypoxemia. Reversal of anesthesia was rapid, smooth, and complete using a combination of atipamezole and sarmazenil IV.

\section{LITERATURE CITED}

Ancrenaz, M. 1994. Use of atipamezole to reverse xylazine tranquilization in captive Arabian oryx (Oryx leucoryx). Journal of Wildlife Diseases 30: 592-595.

Arnemo, J. M., S. R. Moe, and N. E. Soli. 1993. Xylazine-induced sedation in axis deer (Axis axis) and its reversal by atipamezole. Veterinary Research Communications 17: 123-128.

Bettschart-Wolfensberger, R., P. M. Taylor, J. W. Sear, M. R. Bloomfield, K. Rentsch, and S. DAwling. 1996. Physiologic effects of anesthesia induced and maintained by intravenous administration of a climazolam-ketamine combination in ponies premedicated with acepromazine and xylazine. American Journal of Veterinary Research 57: 1472-1477.

Caulkett, N. A. 1997. Anesthesia for North American cervids. The Canadian Veterinary Journal 38: 389-390

, P. H. Cribb, and J. C. Haigh. 2000 Comparative cardiopulmonary effects of carfentanil-xylazine and medetomidine-ketamine used for immobilization of mule deer and mule deer/ white-tailed deer hybrids. Canadian Journal of Veterinary Research 64: 64-68.

European Commission. 2009. Commission regulation (EU) $37 / 2010$ of 22 December 2009. Official
Journal of the European Union, L15/1, 20.1.2010, 1-72.

Fernandez-Moran, J., J. Palomeque, and V. I. Peinado. 2000. Medetomidine/tiletamine/zolazepam and xylazine/tiletamine/zolazepam combinations for immobilization of fallow deer (Cervus dama). Journal of Zoo and Wildlife Medicine 31: $62-64$.

Fragen, R. J. 1997. Pharmacokinetics and pharmacodynamics of midazolam given via continuous intravenous infusion in intensive care units. Clinical Therapeutics 19: 405-419, discussion: 367-408.

Galka, M. E., J. M. Aguilar, M. A. Quevedo, J. M. Santisteban, and R. J. Gomez-Villamandos. 1999. Alpha-2 agonist dissociative anesthetic combinations in fallow deer (Cervus dama). Journal of Zoo and Wildlife Medicine 30: 451453.

Giacometti, M., M. Janovsky, G. Fluch, W. Arnold, AND F. Schober. 2001. A technique to implant heart-rate transmitter in red deer. Wildlife Society Bulletin 29: 586-593.

Haefely, W. 1983. Antagonists of benzodiazepines. Encephalos 9: 143-150.

Hall, L. W., K. W. Clarke, and C. M. Trim. 2001. Veterinary Anaesthesia. 10th Edition. W. B. Saunders, London, UK.

Hall, R. I., F. Szlam, and C. C. Hug, Jr. 1988. Pharmacokinetics and pharmacodynamics of midazolam in the enflurane-anesthetized dog. Journal of Pharmacokinetics and Biopharmaceutics 16: 251-262.

Hudson, R. J. 2001. Role of antlers in the development and sustainability of the world deer industry. In Antler science and product technology, J. S. Sim, H. H. Sunwoo, R. J. Hudson and B. T. Jeon (eds.). ASPT Centre, University of Alberta, Alberta, Canada. pp. 339345.

JaCkson, H. C., AND D. J. NutT. 1992. Effects of benzodiazepine receptor inverse agonists on locomotor activity and exploration in mice. European Journal of Pharmacology 221: 199203.

Jalanka, H. H., and B. O. Roeken. 1990. The use of medetomidine, medetomidine-ketamine combinations, and atipamezole in nondomestic mammals: A review. Journal of Zoo and Wildlife Medicine 21: 259-282.

Janovsky, M., F. Tataruch, M. Ambuehl, and M. Giacometti. 2000. A Zoletil-Rompun mixture as an alternative to the use of opioids for immobilization of feral red deer. Journal of Wildlife Diseases 36: 663-669.

Lin, H. C., J. W. Tyler, E. G. Welles, J. S. Spano, J. C. Thurmon, and D. F. Wolfe. 1993. Effects of anesthesia induced and maintained by continuous intravenous administration of guaifenesin, ketamine, and xylazine in spontaneously breath- 
ing sheep. American Journal of Veterinary Research 54: 1913-1916.

McKelvey, W. A., and C. A. Simpson. 1985. Reversal of the effects of xylazine and xylazine/ketamine in red deer. The Veterinary Record 117: $362-$ 363.

Mich, P. M., L. L. Wolfe, T. M. Sirochman, M. A. Sirochman, T. R. Davis, W. R. Lance, and M. W. Miller. 2008. Evaluation of intramuscular butorphanol, azaperone, and medetomidine and nasal oxygen insufflation for the chemical immobilization of white-tailed deer, Odocoileus virginianus. Journal of Zoo and Wildlife Medicine 39: 480-487.

Miller, B. F., L. I. Muller, T. Doherty, D. A. Osborn, K. V. Miller, and R. J. Warren. 2004. Effectiveness of antagonists for tiletamine-zolazepam/xylazine immobilization in female whitetailed deer. Journal of Wildlife Diseases 40: 533537.

Mosing, M., S. Rezabek, And I. Iff. 2007. Combined anaesthesia with isoflurane and an infusion of a mixture of ketamine, midazolam and one of three alpha-2 adrenoreceptor agonists for castration in horses. Pferdeheilkunde 23: 388-397. [In German.]

Nicholls, P. K., T. A. Bailey, C. A. Baker, and K. Wilson. 1996. Anesthesia of the grey duiker (Sylvicapra grimmia) using a combination of ketamine and xylazine, with reversal by atipa- mezole. Journal of Zoo and Wildlife Medicine 27: 49-53.

Nolan, A., J. Reid, E. Welsh, D. Flaherty, R. McCormack, And A. M. Monteiro. 1996. Simultaneous infusions of propofol and ketamine in ponies premedicated with detomidine: A pharmacokinetic study. Research in Veterinary Science 60: 262-266.

Read, M. R., N. A. Caulkett, A. Symington, and T. K. Shury. 2001. Treatment of hypoxemia during xylazine-tiletamine-zolazepam immobilization of wapiti. Canadian Veterinary Journal 42: 861-864.

Riebold, T. W. 1996. Ruminants. In Veterinary anesthesia, J. C. Thurmon, W. J. Tranquilli and G. J. Benson (eds.). Williams \& Wilkins, Baltimore, Maryland. pp. 610-626.

Stegmann, G. F. 2004. Midazolam/ketamine induction and isoflurane maintenance of anaesthesia in a 2-month-old, hand-raised African buffalo (Syncerus caffer). Journal of the South African Veterinary Association 75: 43-44.

Van Dijk, P., D. P. Lankveld, A. B. Rijkenhuizen, AND F. H. Jonker. 2003. Hormonal, metabolic and physiological effects of laparoscopic surgery using a detomidine-buprenorphine combination in standing horses. Veterinary Anaesthesia and Analgesia 30: 72-80.

Submitted for publication 23 July 2009.

Accepted 2 July 2010. 